\title{
Macrophage Inhibitory Cytokine-1 Induced by a High-Fat Diet Promotes Prostate Cancer Progression by Stimulating Tumor Promoting Cytokine Production from Tumor Stromal Cells
}

\author{
Mingguo Huang \\ Akita University
}

Shintaro Narita

Akita University

Atsushi Koizumi

Akita University

Taketoshi Nara

Akita University

Kazuyuki Numakura

Akita University

\section{Shigeru Satoh}

Akita University

Hiroshi Nanjo

Akita University

Tomonori Habuchi ( $\nabla$ thabuchi@doc.med.akika-u.ac.jp)

Akita University

\section{Research}

Keywords: Macrophage inhibitory cytokine-1, MIC-1, Cancer microenvironment, High-fat diet, Prostate cancer

Posted Date: August 2nd, 2020

DOl: https://doi.org/10.21203/rs.3.rs-51221/v1

License: (c) (1) This work is licensed under a Creative Commons Attribution 4.0 International License. Read Full License 
Version of Record: A version of this preprint was published at Cancer Communications on March 27th, 2021. See the published version at https://doi.org/10.1002/cac2.12137. 


\section{Abstract}

Background: Recent studies have indicated that a high-fat diet (HFD) and/or HFD-induced obesity may influence prostate cancer (PCa) progression, but the role of HFD in PCa microenvironment is unclear.

Methods: In this study, we investigated the role of HFD on PCa stromal microenvironment using the PC3M-luc-C6 PCa model mice fed with HFD or control diet, especially focusing on macrophage inhibitory cytokine-1 (MIC-1) and its effect on the tumor microenvironment. In addition, the synergistic effect of periprostatic adipocytes (PPAC), derived from primary PCa patients, on activation and cytokine secretion of prostate stromal fibroblasts were investigated. The expression pattern and role of MIC-1 signaling on human PCa stroma activation and PCa progression were investigated.

Results: The HFD consumption stimulated PCa cell growth and invasion as a result of upregulated MIC-1 signaling and subsequent increased secretion of interleukin (IL)-8 and IL-6 from prostate stromal fibroblasts in the PC-3M-luc-C6 PCa model mice. In addition, PPAC directly stimulated MIC-1 production from PC-3 cells and IL-8 secretion in prostate stromal fibroblasts through upregulation of the adipolysis and free fatty acid (FFA) release. The increased serum MIC-1 was significantly correlated with human PCa stroma activation, high serum IL-8, IL-6 and lipase activity, advanced PCa progression, and high body mass index of the patients. Glial-derived neurotrophic factor receptor alpha-like (GFRAL), a specific receptor of MIC-1, was highly expressed in both the cytoplasm and membrane of the PCa cells and the surrounding stromal fibroblasts, and the expression level was decreased by androgen deprivation therapy and chemotherapy.

Conclusion: HFD-mediated activation of the PCa stromal microenvironment through metabolically upregulated MIC-1 signaling by increased available free fatty acids may be a critical mechanism of HFD and/or obesity induced PCa progression.

\section{Background}

Prostate cancer ( $\mathrm{PCa}$ ) is one of the most commonly diagnosed cancers and is a leading cause of cancerrelated death in United States and Japan [1, 2]. Recent epidemiological studies have indicated that a highfat diet (HFD) and/or HFD-induced obesity is associated with PCa incidence and progression [3, 4]. Furthermore, several studies, including our own, have shown that a HFD and dietary components may alter gene expression, cellular activity, and induce other important changes in circulating biological factors related to PCa aggressiveness [5-7].

The prostate stromal microenvironment is an interconnected network that consists of various types of stromal cells, and has emerged as a key factor in the growth, and development of PCa [8]. Prostate stromal fibroblasts are a common component of the prostate stroma, and their crosstalk with adjacent cancer cells may influence tumor progression by the secretion of proinflammatory cytokines and growth factors $[9,10]$. Alpha smooth muscle actin (aSMA) is a key marker of cancer associated fibroblasts and reactive stroma, and aSMA overexpressing prostate stroma has been shown to be directly correlated with 
prostate stromal dysfunction, human prostate tumorigenesis and PCa progression $[11,12]$. Macrophage inhibitory cytokine-1 (MIC-1) is a divergent member of the transforming growth factor- $\beta$ family of cytokines, and is a multifunctional and secretory molecule that can exist as either dimeric or monomeric forms [13]. In addition, MIC-1 is a protumorigenic and progressive marker of PCa [14], and recent reports have shown that MIC-1 is expressed in PCa stroma where it can significantly influence cancer cell growth and invasion $[15,16]$. Interestingly, the functional MIC-1 receptor GFRAL, an orphan member of the glialderived neurotrophic factor receptor alpha (GFRa) family, has been shown to interact with MIC-1 and induce important metabolic signaling in mice with HFD-induced obesity [17].

Recent studies have shown that HFD-induced obesity significantly promoted PCa progression through the induction of periprostatic inflammation and cytokine secretion $[18,19]$. In addition, adipocyte infiltration in the ovarian cancer microenvironment has been shown to markedly stimulate cancer cell homing, migration, and invasion through the induction of protumorigenic cytokines such as interleukin (IL)-8 and IL-6 [20]. A HFD and/or HFD-induced obesity may bring physical and chemical changes that modify the PCa microenvironment to promote cancer progression. However, the molecular mechanisms that exist in the altered crosstalk between cancer cells and the surrounding stromal cells in the HFD-induced milieu remain poorly understood.

In this study, we investigated the effect of a HFD on the PCa stromal microenvironment using PC-3M-lucC6 PCa model mice fed with a HFD or a control diet, and found that the MIC-1 signaling upregulated by a HFD and stimulated PCa progression both by direct autocrine mechanisms and indirectly through increased pro-tumorigenic cytokine production in prostate stromal fibroblasts.

\section{Methods}

\section{Cell culture and reagents}

Human prostate cancer (PCa) PC-3, DU145, and LNCaP cells were purchased from American Type Culture Collection (Manassas, VA). The luciferase-expressing PC-3M-luc-C6 cell line derived from PC-3M metastatic PCa cells was purchased from PerkinElmer (Waltham, MA). The cells were maintained in RPMI 1640 or DMEM (Invitrogen, Carlsbad, CA) containing 10\% FBS and 1\% penicillin-streptomycin. The normal PrSC and optimized culture media (Clonetics ${ }^{\mathrm{TM}}$ SCGM $^{\mathrm{TM}}$ Stromal Cell Growth Medium) were purchased from Lonza (Walkersville, MD). Three fatty acids (FAs), including PA, OA, and LA were purchased from Sigma (St. Louis, MO, USA), and the FAs were dissolved in a water with $2 \%$ of Bovine Serum Albumin Fraction V (BSAFV, Sigma) and filtered through a 0.22- $\mu \mathrm{m}$ filter (SLGV004SL; Millipore, Billerica, MA, USA) before use. To assess gene expression in the cultured PCa cells after FA induction, a total of $4 \times 10^{5}$ cells were seeded in a 35-mm dish and treated a day later with various fatty acids $(0.125 \mathrm{mmol} / \mathrm{I}$ of PA, $0.25 \mathrm{mmol} / \mathrm{l}$ of $\mathrm{OA}$, or $0.15 \mathrm{mmol} / \mathrm{l}$ of LA) in serum-free DMEM (Invitrogen) for $24 \mathrm{~h}$. MAPK inhibitor (U0126) and recombinant human MIC-1 (rMIC-1) were purchased from Cell Signaling Technology (Boston, MA) and R\&D Systems (Minneapolis, MN, USA), respectively.

\section{Animal study}


The Institutional Review Board of the Akita University School of Medicine approved all animal experiments. Male 8-week-old BALB/c-nu/nu mice were obtained from Japan SLC (Shizuoka, Japan). A total of $2 \times 10^{6}$ PC-3M-luc-C6 cells were resuspended in $0.1 \mathrm{ml}$ of ice-cold PBS (Invitrogen) and inoculated by intraperitoneal injection into the mice. Two weeks after inoculation, the mice were randomly assigned to two groups (5 per group): control diet (CD) and HFD. The mice in the HFD group were fed with a HFD consisting of $59.9 \%$ calories from fats, $21.4 \%$ from carbohydrates, and $18.6 \%$ from proteins (Purina Mills Test Diets, Richmond, IN), whereas the mice in the CD group were fed with a CE-2 diet (Japan SLC, Shizuoka, Japan). In vivo bioluminescence was used to follow the PC-3M-luc-C6 cell inoculation and invasiveness by the intraperitoneal injection of luciferin ( $200 \mu \mathrm{l}$ at $15 \mathrm{mg} / \mathrm{ml}$ in PBS), and the reflective luciferase activity (60-s exposure) was measured by the Xenogen IVIS ${ }^{\mathrm{TM}}$ imaging system 4 weeks after injection of the cells. The mice were then sacrificed and the tumor burdens in the peritoneal organs were macroscopically evaluated. The tumors were excised and subjected for histopathology, quantitative RTPCR, and intratumoral lipid activity analyses. The blood samples were collected from the orbital sinus, and sera were separated, filtered, and stored at $-80^{\circ} \mathrm{C}$ until use.

\section{Small-interfering RNA (siRNA)-mediated gene knockdown}

MIC-1 siRNA (SI03098480) and GFRAL siRNA (GS389400) were purchased from Qiagen (Valencia, CA), and luciferase siRNA (SI03650353, Qiagen) was used as a control. The siRNAs was transfected using Lipofectamine 2000 (Invitrogen) according to the manufacturer's instructions. The cells were treated with $50 \mathrm{nM}$ siRNAs in a reducing serum RPMI for $12 \mathrm{~h}$ and $24 \mathrm{~h}$. MIC-1 and GFRAL knockdown was verified by quantitative RT-PCR (qRT-PCR).

\section{Human periprostatic adipocyte (PPAC) preparation and co- culture assay}

Human periprostatic adipose tissues were collected from the radical prostatectomies of patients with PCa $(n=13)$ in accordance with the ethics committee of the Akita University School of Medicine. All experiments were performed after obtaining individual written informed consent. Approximately $1 \mathrm{~g}$ of adipose tissues surrounding the prostate were collected during the medical prostatectomy, and fibrosis, clots, and small vessels were macroscopically removed. The adipose tissue was washed twice with cold PBS, before being minced and incubated with $0.075 \%$ Collagenase (Type 1, Funakoshi Co., Ltd, Japan) at $37^{\circ} \mathrm{C}$ for $30 \mathrm{~min}$. Then, the mixtures were centrifuged at $500 \mathrm{~g}$ for $1 \mathrm{~min}$ after dilution with DMEM containing $2 \%$ FBS, and the above fractions were removed and cultured with adipocyte culture medium (Zen-Bio Inc, Durham, NC) as described previously [21]. To investigate the role of periprostatic adipocytes (PPAC) on lipid activities and cytokine production in co-culture with various prostate cells, the isolated adipocytes were directly incubated in 6-well plates that were previously seeded with $2 \times 10^{5} \mathrm{PC}-3$ cells and/or $4 \times 10^{4} \mathrm{PrSC}$ cells in $2 \mathrm{ml}$ of DMEM containing $2 \%$ FBS without antibiotics for $48 \mathrm{~h}$. To evaluate the effect of MIC-1 knockdown on the co-culture cells, the PC-3 cells were pretreated with $50 \mathrm{nM} \mathrm{MIC-1}$ siRNAs for $12 \mathrm{~h}$. The $\mathrm{CM}$ from the monoculture or co-culture plates was then collected and stored at -80 ${ }^{\circ} \mathrm{C}$ until use. 


\section{Adipolysis assay}

The impact of PPAC adipolysis of the co-cultured cells was quantified by the amount glycerol released into the $\mathrm{CM}$, which is proportional to the level of triglyceride storage and the degree of adipolysis using the Adipolyis assay kit (Abcam, Cambridge, UK) according to the manufacturer's instructions. Briefly, $25 \mu \mathrm{l}$ of the $\mathrm{CM}$ from the co-culture plates was incubated with $100 \mu$ of Free Glycerol Assay Reagent for 15 min at room temperature. Then, the absorbance was measured at $540 \mathrm{~nm}$, and the concentration was calculated using the standard curve method.

\section{Lipase activity assay}

Lipase activity in the sera of PCa patients was quantified using the Lipase assay kit (Abcam, Cambridge, UK) to quantify the hydrolyzation of a triglyceride substrate enzymatically. The Institutional Review Board of the Akita University School of Medicine approved all experiments, and samples were used after obtaining individual written informed consent. Briefly, the standards and diluted serum samples were incubated with $100 \mu$ reaction mix and the absorbance was measured at $570 \mathrm{~nm}$ every $3 \mathrm{~min}$ for $30 \mathrm{~min}$. The concentration of glycerol was determined by the standard curve, and the lipase activity was calculated by the linked change of the glycerol. The lipase activity in the sera and tumor extracts of the xenograft mice was measured using the kit.

\section{Free fatty acid (FFA) quantification}

The FFA levels in the extracts of the xenograft and sera of the xenograft mice were quantified in triplicate using the FFA quantification kit (Biovision, Mountain View, CA, USA), according to the manufacturer's instructions. Briefly, $10 \mathrm{mg}$ of the xenografts were homogenized with $200 \mu \mathrm{l}$ chloroform-triton X-100 (1\% triton X-100 in pure chloroform), and the extracts were centrifuged. The purified lipids in the lower phase were collected, air dried, and dissolved in $200 \mu \mathrm{l} \mathrm{FA}$ assay buffer. Fatty acids were converted to their CoA derivatives, and the subsequent oxidized reaction and concomitant generated color were measured at $570 \mathrm{~nm}$. The concentration was calculated using a palmitic acid standard curve, and the secreted FFA level in the CM of the co-culture plates of the cells was measured.

\section{Quantitative RT-PCR}

Total RNAs were extracted from the cultured cells using the TRIzol® reagent (Invitrogen). The following RT-PCR primers were used: IL-8, forward 5'-ATGACTTCCAAGCTGGCCGTGG-3', reverse 5'CATAATTTCTGTTTGGCGCAGTGTGG-3'; IL-6, forward 5'-GCTTTAAGGAGTTCCTGC-3', reverse 5'GGTAAGCCTACACTTTCCA-3'; MIC-1, forward 5'-CGCGCAACGGGGACCACT-3', reverse 5'TGAGCACCATGGGATTGTAGC-3'; GFRAL, forward 5'-GGAGAGTAATGGAAGATGCCTGC-3', reverse 5'GAAGTCATCAGTGCAAAGACACTC-3'; TGF-beta, forward 5'-GACATCAACGGGTTCAC-3', reverse 5'GAAGTTGGCATGGTAGC-3'; beta-actin, forward 5'-ATCTGGCACCACACCTTCTA-3', reverse 5'CGTCATACTCCTGCTTGCTGATCC-3'. The experiments were performed in triplicate.

\section{Cytokine analysis}


$4 \times 10^{4} \mathrm{PrSC}$ cells were seeded in a $35-\mathrm{mm}$ dish containing the optimal growth medium, and cultured with or without $50 \mathrm{ng} / \mathrm{ml} \mathrm{rMIC-1}$ for $24 \mathrm{~h}$. The PrSC cells were co-cultured with $2 \times 10^{5} \mathrm{PC}-3$ cells that were previously treated with $50 \mathrm{nM}$ Ctrl siRNA or MIC-1 siRNA for $24 \mathrm{~h}$. Cytokine levels in the CM described above and in the serum of mice and humans were measured using a cytometric bead array (CBA ${ }^{\mathrm{TM}}, \mathrm{BD}$ Biosciences, San Jose, USA), which can simultaneously measure six proinflammatory cytokines including IL-8, IL-1 $\beta, I L-6, I L-10, T N F a$, and IL-12p70. The procedure was carried out according to the manufacturer's instructions. Briefly, $50 \mu \mathrm{l}$ of chemokine capture bead mixture was incubated with $50 \mu \mathrm{l}$ of each recombinant standard or sample and $50 \mu \mathrm{PE}$-conjugated detection antibody for $2 \mathrm{~h}$ at room temperature. The mixture was then washed to remove unbound PE detection reagent, and the data were acquired using a FACSCalibur flow cytometer (BD Biosciences, Bedford, MA). The levels of cytokines were quantified using CellQuest software (BD Biosciences).

\section{Cell proliferation assay}

$1 \times 10^{4}$ cells were seeded in a 96-well plate and cultured in DMEM containing $2 \%$ FBS without antibiotics. Then, the cells were treated with $50 \mathrm{ng} / \mathrm{ml} \mathrm{rMIC-1}$ for $24 \mathrm{~h}$. The cells were pretreated with $50 \mathrm{nM}$ GFRAL siRNA (siGFRAL) for $12 \mathrm{~h}$ before induction of $\mathrm{rMIC}-1$. Cell proliferation was assessed using a nonradioactive 3-(4,5-dimethylthiazol-2-yl)-2,5-diphenyltetrazolium bromide (MTT)-based cell proliferation assay kit (Roche, Basel, Switzerland).

\section{Matrigel invasion assay}

The in vitro invasion assay was performed in triplicate using Growth Factor Reduced BD BioCoat Matrigel Invasion Chambers (BD Biosciences) according to the manufacturer's instructions. Briefly, $5 \times 10^{4} \mathrm{PCa}$ cells were seeded in the upper chamber and treated with or without $50 \mathrm{ng} / \mathrm{ml} \mathrm{rMIC}-1$. The cells were pretreated with $50 \mathrm{nM}$ siGFRAL for $12 \mathrm{~h}$ before induction of rMIC-1. DMEM containing $20 \%$ FBS was then placed in the lower chamber and incubated for $24 \mathrm{~h}$. Following incubation, the non-invading cells in the upper chamber were removed and the membranes were stained with a Diff-Quik cell-staining kit (Sysmex, Kobe, Japan) to count the invading cells.

\section{Western blotting}

Proteins were extracted from the cultured cells using Complete Lysis-M buffer (Roche, Switzerland). Equal amounts $(10 \mu \mathrm{g})$ of protein were separated by sodium dodecyl sulfate-polyacrylamide gel electrophoresis, transferred to a polyvinylidene difluoride filter (ATTO), and hybridized with corresponding antibodies. The following antibodies were used: Anti-MIC-1 (Cell Signaling), anti-a smooth muscle actin (aSMA, Abcam), anti-ERK1/2, anti-phospho-ERK1/2 (P-ERK1/2, Thr202/Tyr204, Cell Signaling), and antibeta-actin (Cell Signaling) antibody.

\section{Determination of serum level of MIC-1}

Human serum samples were obtained from 67 patients with PCa. The Institutional Review Board of the Akita University School of Medicine approved all experiments, and the samples were obtained after written informed consent. The serum MIC-1 level was measured using an MIC-1 ELISA Kit (Oxford 
Biomedical Research, Inc., Oxford, MI, USA) according to the manufacturer's instructions. The mouse serum level of MIC-1 was measured using the MIC-1 ELISA kit according to the manufacturer's instructions.

\section{Histopathological analysis}

Slides containing tissue samples from radical prostatectomy specimens were obtained from Akita University Hospital. The immunohistochemical expression of GFRAL, MIC-1, and aSMA in human PCa tissues were evaluated using a GFRAL rabbit polyclonal antibody (1:200, Abcam), rabbit anti-human MIC1 polyclonal antibody (1:100, Cell Signaling), and rabbit anti-aSMA (1:200, Abcam). The methods of immunohistochemical staining were previously described [22]. The expression levels were scored by investigators ( $\mathrm{MH}$ and $\mathrm{HN}$ ) who were blinded to the patients' background and clinicopathological information. The GFRAL and MIC-1 staining intensities in the cancer cells and stromal cells were scored on a semiquantitative scale as follows: 1 , negative and/or low; 2 , moderate; and 3 , strong. The percentage of stromal aSMA-positive cells in the stroma was evaluated and divided into low ( $\leqslant 5 \%)$, moderate (5$20 \%$ ), and high (> 20\%) groups based on the proportion of positive cells. Hematoxylin and eosin staining was performed in the in vivo xenograft tumors, and the degree of invasiveness of the inoculated tumor cells into the intraperitoneal organs was microscopically evaluated. The percentage of Ki67 positive cells in 400-500 tumor cells in the area containing the highest density of the xenograft tumor was evaluated using an anti-Ki67 antibody (1:800; Cell Signaling Technology).

\section{Statistical analyses}

All statistical analyses were performed using SPSS ver12 software. All the values are presented as mean \pm SD. Statistical significance was evaluated by an unpaired Student's $t$-test or analysis of variance repeated measurement for comparison between two or three means in each experiment. Differences were considered statistically significant at $P<0.05$.

\section{Results}

HFD enhances PCa progression, adipocyte infiltration, and adipolysis in the tumor microenvironment in vivo

The PCa model were generated by intraperitoneally inoculating PC-3M-luc-C6 cells with stable luciferase expression, and randomly divided the mice into HFD and control diet (CD) groups fed with a HFD or CE-2 diet, respectively. Tumor progression was evaluated using an IVIS imaging system four weeks after inoculation of the cells. The extent of tumor burden, as evaluated by luciferase activity, was significantly higher in the HFD group than in the CD group (Fig. 1a). The Ki67 positivity was significantly higher in the HFD group than in the CD group by immunohistochemistry ( $28.3 \pm 5.3 \%$ vs $13.9 \pm 2.1 \%, * P<0.05$; Fig. 1 b) In addition, the hematoxylin and eosin staining of the mouse peritoneum tumor demonstrated a higher transmigration of PC-3M-luc-C6 PCa cells into the peritoneum stroma in the HFD group than in the CD group (arrow in the middle panel, Fig. 1c). Interestingly, a HFD markedly stimulated adipocyte infiltration to the xenograft tumor microenvironment (Fig. 1c, right). A recent report has shown that the adipocytes 
surrounding tumor cells may provide many types of nutrients, such as fatty acids (FAs), for growing tumor cells by increasing adipolysis [23]. In line with this observation, we investigated the role of adipocytes in the tumor microenvironment by measuring lipase activity in both the xenograft tumor extract and the serum with a lipase activity assay kit. The lipase activity was markedly higher in the HFD group than the CD group ( $P<0.05$ and $P<0.05$, respectively; Fig. $1 \mathrm{~d}$ and $1 \mathrm{e})$. In addition, we measured the level of acid FFAs in the xenograft extracts and serum using a FFA quantification kit. We demonstrated that the FFA level was significantly higher in the HFD group than in the CD group $\left({ }^{\star} P<0.05\right.$ and ${ }^{* \star} P<0.01$, respectively; Fig. $1 \mathrm{f}$ and $1 \mathrm{~g}$ ). These findings suggest that a HFD influences PCa progression and enhances adipocyte infiltration and lipolysis in the PCa microenvironment.

\section{HFD and exogenous FFAs enhance the expression and secretion of MIC-1 in vivo and in vitro.}

MIC-1 is a divergent member of the transforming growth factor- $\beta$ family [24], and has been shown to be expressed in both PCa cells and in prostate stromal fibroblasts $[15,16]$. Therefore, we investigated the expression of MIC-1 and glial-derived neurotrophic factor receptor alpha-like (GFRAL), the cognate receptor of MIC-1, semi-quantitatively by immunohistochemistry using the mouse xenograft tumor sample. We demonstrated that although the expression level of MIC-1 was significantly higher in the HFD group than in the CD group ( $P<0.05$, Fig. 2a), there was no statistical difference in the expression of GFRAL between the two groups (Fig. 2a). In addition, the mean serum level of MIC-1 was significantly higher in the HFD group than in the CD group $(3506.0 \pm 1888.4$ and $2618.8 \pm 710.4 \mathrm{pg} / \mathrm{ml}, P<0.05$; Fig. 2b). Considering the accumulating evidence suggesting that palmitic acid (PA) stimulates MIC-1 expression in many types of cancer cells [7, 25], we examined the role of increased FFAs on MIC-1 expression under a HFD condition. The mRNA expression level of MIC-1, but not GFRAL and TGF-beta, was significantly higher in PCa LNCaP, PC3, and DU145 cells after treatment with $0.125 \mathrm{mmol} / \mathrm{l}$ of PA, $0.25 \mathrm{mmol} / \mathrm{I}$ of oleic acid (OA), or $0.15 \mathrm{mmol} / \mathrm{I}$ of linoleic acid (LA) (Figure S1 and Fig. 2c). In addition, the expression of monomeric and dimeric MIC-1 (molecular weight, $\sim 14 \mathrm{kDa}$ and $\sim 28 \mathrm{kDa}$, respectively) was markedly increased in the conditioned medium (CM) of PC-3 cells treated with FFAs compared with that of the PC-3 cells cultured with $2 \%$ BSA as control (Fig. 2d). The proliferation rate was significantly higher in the PC-3 and PC-3M-luc-C6 cells following treatment with $50 \mathrm{ng} / \mathrm{ml} \mathrm{rMIC-1}$, and the effect was attenuated by pretreatment with $50 \mathrm{nM}$ GFRAL siRNA for $12 \mathrm{~h}$ (Figure S2a). Similarly, the invasive capacity of PC-3 and PC-3M-luc-C6 cells was significantly increased by treatment with rMIC-1, and the effect was abrogated by pretreatment with GFRAL siRNA (Figure S2b). These findings suggest that enhanced FFA release in the tumor microenvironment through upregulated adipolysis stimulated the expression and secretion of MIC-1 in tumor cells under the HFD condition, and that the MIC-1-GFRAL signaling stimulated PCa progression.

\section{Activation and cytokine secretion in PCa stromal fibroblasts by upregulated MIC-1 in the HFD condition}

The expression level of aSMA, a activation marker of stromal fibroblasts was significantly higher in the xenograft tumor of HFD group than in the CD group ( $P<0.05$; Fig. 3a), We measured the mouse serum cytokine levels using a human cytokine cytometric bead array for IL-8, IL-1ß, IL-6, IL-10, TNFa, and IL- 
12p70, and the mean IL-8 level was significantly higher in the HFD group than in the CD group (1358.9 \pm 528.5 and $773.2 \pm 210.7 \mathrm{pg} / \mathrm{ml}$, respectively, $P<0.05 ;$ Fig. $3 \mathrm{~b}$ ). Next, we evaluated the relationship between the increased cytokine secretion in prostate stromal cells (PrSC) and the upregulated MIC-1 in PCa cells. The IL-8 and IL-6 levels were significantly increased by 3.4- and 3.2-fold, respectively in the CM of PrSC cells treated with $50 \mathrm{ng} / \mathrm{ml} \mathrm{rMIC-1}$ compared to untreated PrSC, and were increased by 4.7- and 5.4-fold in the CM of PrSC cells co-cultured with PC-3 cells. However, the effect was markedly abrogated by pretreatment of the PC-3 cells with 50 nM MIC-1 siRNA (siMIC-1) for $12 \mathrm{~h}$ (Fig. 3c). Similarly, the IL-8 and IL- 6 levels were significantly higher in the CM of the PrSC cells co-cultured with DU145 cells compared to those cultured alone or co-cultured with DU145 cells pretreated with siMIC-1 for $12 \mathrm{~h}$ (Figure S3). In addition, the expression of aSMA was significantly upregulated in PrSC cells by treatment with $50 \mathrm{ng} / \mathrm{ml} \mathrm{rMIC-1}$, and the phospho-ERK1/2 (pERK1/2) expression was also upregulated in PrSC cells in response to treatment with rMIC-1 (Fig. 3d). The mRNA expression levels of $I L-8$ and $I L-6$ were markedly increased in PrSC cells by treatment with $50 \mathrm{ng} / \mathrm{ml} \mathrm{rMIC-1}$, and the effect was attenuated by pretreatment with $1 \mu \mathrm{M}$ U0126, an ERK kinase inhibitor (Fig. 3e). These findings suggest that upregulated MIC-1 in PCa cells stimulates the surrounding stromal fibroblasts, resulting in increased secretion of protumorigenic cytokines such as IL- 8 and IL- 6 through activation of the ERK signaling pathway in the PCa microenvironment under a HFD condition.

\section{Periprostatic adipocytes directly stimulated MIC-1 secretion in PCa cells and subsequently increased IL-8 secretion in PrSC through upregulated adipolysis and FFA release in a direct co-culture system}

To address the functional role of periprostatic adipocytes on MIC-1 and cytokine expression in the PCa stromal microenvironment, a co-culture assay was performed by direct incubation of periprostatic adipocytes (PPACs) with PC-3 cells and/or PrSC cells. The isolated PPACs from the radical prostatectomies of PCa patients $(n=13)$ were directly incubated in 6-well plates previously seeded $2 \times 10^{5}$ PC-3 cells pretreated with or without $50 \mathrm{nM}$ siMIC-1, and further in the presence or absence of $4 \times 10^{4}$ PrSC cells in DMEM containing for $48 \mathrm{~h}$. The levels of adipolysis and FFA release were significantly higher in the CM harvested from the co-culture of PPAC with PC-3 cells in the CM from the PPAC culture alone, regardless of in the presence or absence of PrSC cells ( $* P<0.05$ and $\star \star P<0.01$; Fig. 4 a and $4 \mathrm{~b}$ ). Interestingly, the levels of adipolysis and FFA release were also increased in the co-culture of PPAC and PC-3 cells pretreated with siMIC-1 (Fig. 4a and 4b). In addition, the MIC-1 level was significantly higher in the CM of the co-culture of PC-3 cells and PPAC, regardless of the presence, or absence of PrSC cells $(5178.0 \pm 801.8$ vs $1883.6 \pm 143.1 \mathrm{pg} / \mathrm{ml}$, and $4597.7 \pm 723.0$ vs $1883.6 \pm 143.1$, respectively). On the contrary, the MIC-1 level was significantly decreased by pretreatment of PC-3 with siMIC-1 in co-culture with PPAC ( ${ }^{\star *} P<0.01$ and ${ }^{* \star} P<0.01$, Fig. 4c). The IL-8 level was significantly higher in the CM of the coculture of PrSC cells and PPAC, and further significantly increased in the co-presence of PC-3 cells than that of in the CM of PrSC cells, PC-3 cells or PPAC single culture, or PrSC cells and PPAC co-culture, respectively $(6697.7 \pm 1673.5 \mathrm{vs} 1266.7 \pm 147.9 \mathrm{pg} / \mathrm{ml}$, and $6697.7 \pm 1673.5 \mathrm{vs} 2688.4 \pm 401.6$, respectively). Furthermore, IL-8 was markedly decreased in the CM of the co-culture of PrSC cells and PC3 cells when the PC- 3 cells were pretreated with siMIC- 1 compared to the co-culture of native PC- 3 cells, 
PPAC, and PrSC cells ( ${ }^{\star} P<0.05$, Fig. 4 d). These findings strongly suggest that the periprostatic adipocytes in the tumor microenvironment have bidirectional crosstalk with PCa cells and the surrounding stromal cells, and enhance PCa progression through the upregulation of MIC-1 in PCa cells. This in turn, is thought to enhance IL-8 production from PrSC cells, especially under conditions of a HFD and/or HFD-mediated obesity.

\section{Overexpression and secretion of MIC-1 was correlated with cancer stroma activation, high serum level of proinflammatory cytokines, high body mass index and serum lipase activity, and advanced human PCa progression}

To further determine the role of MIC-1 in human PCa progression, we performed MIC-1 and aSMA immunohistochemistry in specimens of $67 \mathrm{PCa}$ patients treated by radical prostatectomy. MIC-1 was highly expressed in PCa cells and was also expressed in the surrounding tumor stromal cells (Figure S4). aSMA was predominantly expressed in the PCa stroma, and the staining level of aSMA in PCa specimens was calculated according to the proportion of aSMA-positive cells (Fig. 5a). In addition, we measured the serum MIC-1 in the PCa patient and divided the samples into two groups (high and low) according to the median serum level of MIC-1 (MIC-1-low group, 735.0 $\pm 67.1 \mathrm{pg} / \mathrm{ml}, n=33$; and MIC-1-high group, 1206.9 $\pm 274.3 \mathrm{pg} / \mathrm{ml}, n=34)$. The aSMA staining levels and serum levels of IL-8 and IL-6 were compared between the two groups. In subjects, with the low serum MIC-1-level (MIC-1-low group), 51.5\%, 36.4\%, and $12.1 \%$ were classified as low, moderate, and high aSMA staining, respectively, while $29.4 \%, 38.2 \%$, and $32.4 \%$ of subjects with high MIC-1 levels (MIC-1-high group) were classified as low, moderate, and high aSMA staining $(P=0.011$, Fig. $5 b)$. In addition, the mean serum level of IL-8 and IL- 6 was significantly higher in the MIC-1-high group than the MIC-1-low group (IL-8: $230.1 \pm 395.0$ and $61.4 \pm 145.9 \mathrm{pg} / \mathrm{ml}, P=$ 0.035 ; and IL-6: $10.0 \pm 17.5$ and $3.0 \pm 3.5 \mathrm{pg} / \mathrm{ml} P=0.044$, respectively, Fig. $5 \mathrm{c}$ and $5 \mathrm{~d}$ ). In addition, the serum MIC-1 levels were compared between the patients with a low PSA $(<10 \mathrm{ng} / \mathrm{dl}, n=45)$ level and those with a high PSA ( $\geq 10 \mathrm{ng} / \mathrm{dl}, n=22$ ) level, and patients with a low Gleason score (GS, $<7, n=43$ ) and those with a high GS $(\geq 7, n=24)$. The serum MIC-1 levels were significantly higher in the high PSA group than in the low PSA group $(1080.1 \pm 297.9$ and $897.7 \pm 238.8 \mathrm{pg} / \mathrm{ml}$, respectively, $P=0.009$, Fig. $5 \mathrm{e})$, and also higher in the high GS group than in the low GS group $(996.1 \pm 241.7$ and $887.8 \pm 200.6 \mathrm{pg} / \mathrm{ml}$, respectively, $P=0.074$, Fig. $5 f$ ). In addition, when the patients were divided into two groups according to median body mass index (BMI), the mean serum MIC-1 level was significantly higher in the high BMI group than in the low BMl group $(984.2 \pm 254.1, n=33$, and $863.3 \pm 179.2 \mathrm{pg} / \mathrm{ml}, n=34$, respectively, $P=$ 0.037 , Fig. $5 \mathrm{~g}$ ). When the patients were divided into two groups according to median serum lipase activity, the serum MIC-1 levels were significantly higher in the high lipase activity group than in the low lipase activity group (1064.8 $\pm 329.1, n=27$, and $845.2 \pm 207.7 \mathrm{pg} / \mathrm{ml}, n=40$, respectively; $P=0.001$; Fig. $5 \mathrm{~h}$ ). These findings strongly suggest that the overexpression and secretion of MIC-1 may play an important role in PCa progression by enhanced secretion of proinflammatory cytokines through the activation of stromal fibroblasts.

GFRAL is expressed in PCa cells and surrounding stromal fibroblasts, and expression is affected by androgen deprivation therapy and chemotherapy

Page $11 / 25$ 
To determine the role of GFRAL, a MIC-1 functional receptor, on PCa progression, we performed GFRAL immunohistochemistry in specimens from PCa patients who underwent radical prostatectomy. GFRAL was predominantly expressed in the cytoplasm and membrane of PCa cells, and also in the surrounding stromal fibroblasts (Fig. 6a). The staining level of GFRAL tended to be lower in the specimens from patients who received neoadjuvant therapy, but the difference was not significant (None, $n=10$ and NEO, $n=9, P=0.208$, Fig. 6b). Furthermore, the GFRAL staining level was significantly lower in the stromal fibroblasts of patients who received neoadjuvant chemohormonal therapy than in those who did not (None, $n=10$ and NEO, $n=9, P=0.017$, Fig. $6 \mathrm{~b}$ ). In addition, as shown in Figure S5, the mRNA level of $I L-8$ and $I L-6$ in PrSC cells that was upregulated by rMIC- 1 was significantly abrogated by pretreatment of $50 \mathrm{nM}$ sigFRAL. Thus, GFRAL expression may be essential for stimulation of cytokine expression in stromal fibroblasts, as well as for the secretion of MIC-1 from PCa cells. These findings also suggest that MIC-1-GFRAL signaling in the tumor microenvironment plays a critical role in PCa progression by affecting the interaction between PCa cells and stromal fibroblasts.

\section{Discussion}

Although several reports have shown that HFD consumption enhanced PCa progression through cytokine signaling, such as MIC-1, MCP-1, IL-8, and IL-6, the underling mechanism of increased cytokine secretion has not been fully delineated $[6,7,26]$. Prostate stromal fibroblasts represent a major component of prostate stroma, and may play an important role in PCa tumorigenesis and cancer progression via the secretion of proinflammatory cytokines [9]. A recent report has shown that many type of cytokines, such as CXCL-1, CXCL-2 CXCL-3, and IL-8, are produced by prostate stromal cells by the stimulation of IL-1 secreted by prostate epithelial cells [10]. In addition, periprostatic adipocytes may facilitate metastatic extension of PCa cells by enhanced CCR3/CCL7 signaling in HFD-induced obesity [18]. In this study, IL-8 and IL- 6 were secreted in activated prostate stromal fibroblasts as a consequence of elevated MIC-1 signaling in PCa cells affected by HFD-mediated adipocyte infiltration and FFA release in the tumor microenvironment of the PCa xenograft model mice. In addition, IL-8 secretion was significantly increased in PrSC cells by upregulated MIC-1 in PC-3 cells stimulated by periprostatic adipocytes in a direct co-culture system of the cells, These findings suggest that a HFD enhances MIC-1 expression and secretion in PCa cells, and the enhanced MIC-1 stimulates the prostate stromal cells to increase the expression and secretion of protumorigenic cytokines such as IL-8 and II-6 (Fig. 7). According to the accumulation evidence of the involvement of IL- 6 and IL-8 in the progression of PCa [27-30], our results indicate that the tumor promoting crosstalk between PCa cells and the stroma of tumor microenvironment is caused by HFD-induced PCa phenotype alteration (Fig. 7).

MIC-1 is a transforming growth factor- $\beta$ family molecule, and the overexpression and enhanced secretion of MIC-1 has been shown to stimulate PCa cell proliferation, invasion, and also involved in anti-cancer therapy resistance $[14,31,32]$. In addition, MIC-1 is a known stress-responsible molecule, and its expression and secretion has been shown to be affected by multiple factors or conditions such as tumor suppressor molecular p53, drugs, dietary palmitic acid, and hypoxia [7, 31, 32]. In the present study, HFD consumption was associated with prominent adipocyte infiltration to the xenograft stroma and 
significantly higher lipase activity and FFA release in both the tumor tissue and serum of the PCa xenograft mouse. In addition, the expression and secretion of MIC-1 was directly stimulated by several exogenous FFAs such as PA, OA, and LA in PCa cells. Furthermore, the enhanced FFA release in PPAC significantly stimulated the expression and secretion of MIC-1 in PCa cells following direct co-culture with PPAC. Although the underling mechanism of upregulated adipocyte infiltration and adipolysis in the xenograft tumor microenvironment is unclear, a recent report also showed that dietary enhanced expression of lipoprotein lipase and the subsequent increase of FFA secretion were required for the growth of PCa cells, and the alteration of adipocytes may be influenced by PCa cells [23]. These findings, including those of the current study, may suggest that the increase in FFAs in the tumor microenvironment by enhanced periprostatic adipocytes lipolysis is one of mechanisms that promotes MIC-1 expression in PCa cells. Moreover, metabolically activated MIC-1 signaling may play an important role in HFD-induced PCa progression.

The MIC-1 functional receptor GFRAL has been shown to be highly expressed in the hindbrain and at a low-level in adipose tissue, and may play a critical role in resistance to obesity in HFD-fed mice [33, 34]. In addition, the binding MIC-1 with GFRAL can activate many intracellular signaling cascades, such as AKT and ERK1/2, through the tyrosine kinase co-factor RET [34]. In this study, we found that GFRAL was expressed in PCa cells and the surrounding stromal fibroblasts, and the expression of GFRAL was linked with the effect of cancer neoadjuvant chemotherapy. Interestingly, while there was no significant difference in GFRAL expression in the xenograft PCa tumor tissue of the two diet groups, the MIC-1mediated PCa cell proliferation, invasiveness, and cytokine secretion of PrSC were significantly abrogated by treatment of GFRAL specific siRNA. These findings strongly suggest that MIC-1/GFRAL signaling may stimulate $\mathrm{PCa}$ progression indirectly by promoting the expression and secretion of protumorigenic cytokines from cancer stromal cells in the tumor microenvironment, resulting in direct and indirect the enhanced proliferating signaling cascade in PCa cells.

The direct role of MIC-1/GFRAL signaling in adipocyte lipolysis was unclear from the present study. A recent report has shown that the administration of recombinant MIC-1 significantly inhibited adiposity, metabolic dysfunction, and cytokine secretion through reduced food intake and body weight in mice fed with a HFD [33]. However, in this study, there was no significant difference in the level of adipolysis and FFA release in isolated periprostatic adipocytes following direct co-culture with PCa PC-3 cells compared to that of the PC-3 cells pretreated with MIC-1 siRNA (Fig. 4a and 4b). A previous study suggested that the direct interaction of MIC-1 with the cognate receptor GFRAL in the brain is required for metabolic effects [17]. Therefore, while MIC-1 may have a role as an endocrine signaling molecule for systemic metabolic effects by the engagement of GFRAL in brain, it may also promote cancer progression by directly stimulating cancer cells in an autocrine manner, and by activating the cancer-promoting interaction between cancer cells and stromal cells in tumor microenvironment.

\section{Conclusions}


In summary, we found that HFD facilitated adipocyte infiltration and FFA secretion in the tumor microenvironment, and enhanced MIC-1 expression in PCa cells. The high level of MIC-1 can subsequently activate PCa stromal fibroblasts to secrete protumorigenic cytokines, including IL6 and IL8[27-30], in the PCa microenvironment, and augment PCa progression. In addition, it has been suggested that the higher activity in the MIC-1/GFRAL signaling was clinically associated with PCa progression through the activation and cytokine production in prostate stromal fibroblasts in human PCa specimens. Therefore, MIC-1 signaling in the PCa microenvironment may be an important target for chemoprevention and therapy in PCa.

\section{Abbreviations}

MIC-1: Macrophage inhibitory cytokine-1;

rMIC-1: Recombinant MIC-1

GFRAL: Glial-derived neurotrophic factor receptor alpha-like;

PPAC: Periprostatic adipocytes;

PrSC: prostate stromal fibroblasts;

FFA: Free fatty acid;

IL-8/IL-6: Interleukin (IL)-8/ Interleukin (IL)-6;

aSMA: a smooth muscle actin;

siRNA: Small interfering RNA;

siMIC-1: Macrophage inhibitory cytokine-1 siRNA;

siGFRAL: Glial-derived neurotrophic factor receptor alpha-like siRNA;

Ctrl siRNA: Control siRNA;

PCa: Prostate cancer;

HFD: High-fat diet;

CD: Control diet;

\section{Declarations}

\section{Acknowledgements}


Not applicable.

\section{Author contributions}

M.H. and T.H. conceived the project and designed experiments. M.H., A.K. T.N. and H.N. performed the experiments. M.H., S.N., A.K., T.N., K.N. S.S. H.N. and T.H. analyzed the data. M.H., S.N. and T.H. wrote the manuscript.

\section{Funding}

This work was supported by the Japan Society for the Promotion of Science (JSPS, Grant No.: 16H02679, 16K10992, 19K09663) and AMED-CREST, Japan Agency for Medical Research and Development (AMED).

\section{Ethics approval and consent to participate}

The Institutional Review Board of the Akita University School of Medicine approved all experiments, and the all experiments were performed after obtaining individual written informed consent.

Animal studies were approved by the Committee for Ethics in Animal Experimentation of Akita University School of Medicine and were performed according to the Guideline for Animal Experiments, and these studies met the ethical standards required by the law and the guidelines on the use of experimental animals in Japan.

\section{Consent for publication}

Not applicable.

\section{Competing of interests}

None.

\section{References}

1. Jemal A, Siegel R, Ward E, Murray T, Xu J, Thun MJ: Cancer statistics, 2007. CA Cancer J Clin 2007, 57(1):43-66.

2. Ito K: Prostate cancer in Asian men. Nat Rev Urol2014, 11(4):197-212.

3. Calle EE, Rodriguez C, Walker-Thurmond K, Thun MJ: Overweight, obesity, and mortality from cancer in a prospectively studied cohort of U.S. adults. N Engl J Med 2003, 348(17):1625-1638.

4. Wu S, Powers S, Zhu W, Hannun YA: Substantial contribution of extrinsic risk factors to cancer development. Nature 2016, 529(7584):43-47.

5. Narita S, Tsuchiya N, Saito M, Inoue T, Kumazawa T, Yuasa T, Nakamura A, Habuchi T: Candidate genes involved in enhanced growth of human prostate cancer under high fat feeding identified by microarray analysis. The Prostate 2008, 68(3):321-335. 
6. Huang M, Narita S, Numakura K, Tsuruta H, Saito M, Inoue T, Horikawa Y, Tsuchiya N, Habuchi T: A high-fat diet enhances proliferation of prostate cancer cells and activates MCP-1/CCR2 signaling. The Prostate 2012, 72(16):1779-1788.

7. Huang M, Narita S, Inoue T, Tsuchiya N, Satoh S, Nanjo H, Sasaki T, Habuchi T: Diet-induced macrophage inhibitory cytokine 1 promotes prostate cancer progression. Endocrine-related cancer 2014, 21(1):39-50.

8. Barron DA, Rowley DR: The reactive stroma microenvironment and prostate cancer progression. Endocrine-related cancer 2012, 19(6):R187-204.

9. Ao M, Franco OE, Park D, Raman D, Williams K, Hayward SW: Cross-talk between paracrine-acting cytokine and chemokine pathways promotes malignancy in benign human prostatic epithelium. Cancer Res 2007, 67(9):4244-4253.

10. Kogan-Sakin I, Cohen M, Paland N, Madar S, Solomon H, Molchadsky A, Brosh R, Buganim Y, Goldfinger N, Klocker $\mathrm{H}$ et al: Prostate stromal cells produce CXCL-1, CXCL-2, CXCL-3 and IL-8 in response to epithelia-secreted IL-1. Carcinogenesis 2009, 30(4):698-705.

11. Hayward SW, Wang Y, Cao M, Hom YK, Zhang B, Grossfeld GD, Sudilovsky D, Cunha GR: Malignant transformation in a nontumorigenic human prostatic epithelial cell line. Cancer Res 2001, 61(22):8135-8142.

12. Tuxhorn JA, Ayala GE, Smith MJ, Smith VC, Dang TD, Rowley DR: Reactive stroma in human prostate cancer: induction of myofibroblast phenotype and extracellular matrix remodeling. Clinical cancer research : an official journal of the American Association for Cancer Research 2002, 8(9):2912-2923.

13. Bootcov MR, Bauskin AR, Valenzuela SM, Moore AG, Bansal M, He XY, Zhang HP, Donnellan M, Mahler S, Pryor K et al: MIC-1, a novel macrophage inhibitory cytokine, is a divergent member of the TGF-beta superfamily. Proc Natl Acad Sci U S A 1997, 94(21):11514-11519.

14. Bauskin AR, Brown DA, Kuffner T, Johnen H, Luo XW, Hunter M, Breit SN: Role of macrophage inhibitory cytokine-1 in tumorigenesis and diagnosis of cancer. Cancer Res 2006, 66(10):4983-4986.

15. Bruzzese F, Hagglof C, Leone A, Sjoberg E, Roca MS, Kiflemariam S, Sjoblom T, Hammarsten P, Egevad L, Bergh A et al: Local and systemic protumorigenic effects of cancer-associated fibroblastderived GDF15. Cancer Res 2014, 74(13):3408-3417.

16. Bauskin AR, Brown DA, Junankar S, Rasiah KK, Eggleton S, Hunter M, Liu T, Smith D, Kuffner T, Pankhurst GJ et al: The propeptide mediates formation of stromal stores of PROMIC-1: role in determining prostate cancer outcome. Cancer Res 2005, 65(6):2330-2336.

17. Emmerson PJ, Wang F, Du Y, Liu Q, Pickard RT, Gonciarz MD, Coskun T, Hamang MJ, Sindelar DK, Ballman KK et al: The metabolic effects of GDF15 are mediated by the orphan receptor GFRAL. Nat Med 2017, 23(10):1215-1219.

18. Laurent V, Guerard A, Mazerolles C, Le Gonidec S, Toulet A, Nieto L, Zaidi F, Majed B, Garandeau D, Socrier $Y$ et al: Periprostatic adipocytes act as a driving force for prostate cancer progression in obesity. Nat Commun 2016, 7:10230. 
19. Zhang T, Tseng C, Zhang Y, Sirin O, Corn PG, Li-Ning-Tapia EM, Troncoso P, Davis J, Pettaway C, Ward $\mathrm{J}$ et al: CXCL1 mediates obesity-associated adipose stromal cell trafficking and function in the tumour microenvironment. Nat Commun 2016, 7:11674.

20. Nieman KM, Kenny HA, Penicka CV, Ladanyi A, Buell-Gutbrod R, Zillhardt MR, Romero IL, Carey MS, Mills GB, Hotamisligil GS et al: Adipocytes promote ovarian cancer metastasis and provide energy for rapid tumor growth. Nat Med 2011, 17(11):1498-1503.

21. Carswell KA, Lee MJ, Fried SK: Culture of isolated human adipocytes and isolated adipose tissue. Methods Mol Biol 2012, 806:203-214.

22. Huang M, Koizumi A, Narita S, Inoue T, Tsuchiya N, Nakanishi H, Numakura K, Tsuruta H, Saito M, Satoh $\mathrm{S}$ et al: Diet-induced alteration of fatty acid synthase in prostate cancer progression. Oncogenesis 2016, 5:e195.

23. Kuemmerle NB, Rysman E, Lombardo PS, Flanagan AJ, Lipe BC, Wells WA, Pettus JR, Froehlich HM, Memoli VA, Morganelli PM et al: Lipoprotein lipase links dietary fat to solid tumor cell proliferation. Mol Cancer Ther 2011, 10(3):427-436.

24. Mimeault M, Batra SK: Divergent molecular mechanisms underlying the pleiotropic functions of macrophage inhibitory cytokine-1 in cancer. J Cell Physiol 2010, 224(3):626-635.

25. Kim JH, Kim KY, Jeon JH, Lee SH, Hwang JE, Lee JH, Kim KK, Lim JS, Kim KI, Moon EY et al: Adipocyte culture medium stimulates production of macrophage inhibitory cytokine 1 in MDA-MB231 cells. Cancer Lett 2008, 261(2):253-262.

26. Huang M, Narita S, Inoue T, Koizumi A, Saito M, Tsuruta H, Numakura K, Satoh S, Nanjo H, Sasaki T et al: Fatty acid binding protein 4 enhances prostate cancer progression by upregulating matrix metalloproteinases and stromal cell cytokine production. Oncotarget 2017, 8(67):111780-111794.

27. Culig Z, Puhr M: Interleukin-6 and prostate cancer: Current developments and unsolved questions. Mol Cell Endocrinol 2018, 462(Pt A):25-30.

28. Liu Q, Li A, Tian Y, Wu JD, Liu Y, Li T, Chen Y, Han X, Wu K: The CXCL8-CXCR1/2 pathways in cancer. Cytokine Growth Factor Rev 2016, 31:61-71.

29. Maxwell PJ, Coulter J, Walker SM, McKechnie M, Neisen J, McCabe N, Kennedy RD, Salto-Tellez M, Albanese C, Waugh DJ: Potentiation of inflammatory CXCL8 signalling sustains cell survival in PTEN-deficient prostate carcinoma. Eur Urol 2013, 64(2):177-188.

30. Peinado H, Zhang H, Matei IR, Costa-Silva B, Hoshino A, Rodrigues G, Psaila B, Kaplan RN, Bromberg JF, Kang Y et al: Pre-metastatic niches: organ-specific homes for metastases. Nat Rev Cancer 2017, 17(5):302-317.

31. Zhao L, Lee BY, Brown DA, Molloy MP, Marx GM, Pavlakis N, Boyer MJ, Stockler MR, Kaplan W, Breit $\mathrm{SN}$ et al: Identification of candidate biomarkers of therapeutic response to docetaxel by proteomic profiling. Cancer Res 2009, 69(19):7696-7703.

32. Mimeault M, Johansson SL, Batra SK: Marked improvement of cytotoxic effects induced by docetaxel on highly metastatic and androgen-independent prostate cancer cells by downregulating macrophage inhibitory cytokine-1. Br J Cancer 2013, 108(5):1079-1091. 
33. Tsai VW, Zhang HP, Manandhar R, Lee-Ng KKM, Lebhar H, Marquis CP, Husaini Y, Sainsbury A, Brown DA, Breit SN: Treatment with the TGF-b superfamily cytokine MIC-1/GDF15 reduces the adiposity and corrects the metabolic dysfunction of mice with diet-induced obesity. Int J Obes (Lond) 2018, 42(3):561-571.

34. Mullican SE, Lin-Schmidt X, Chin CN, Chavez JA, Furman JL, Armstrong AA, Beck SC, South VJ, Dinh TQ, Cash-Mason TD et al: GFRAL is the receptor for GDF15 and the ligand promotes weight loss in mice and nonhuman primates. Nat Med 2017, 23(10):1150-1157.

\section{Figures}

Fig. 1

a

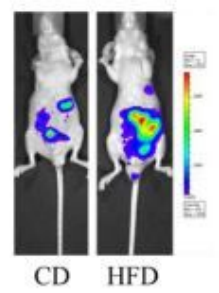

$\mathrm{b}$

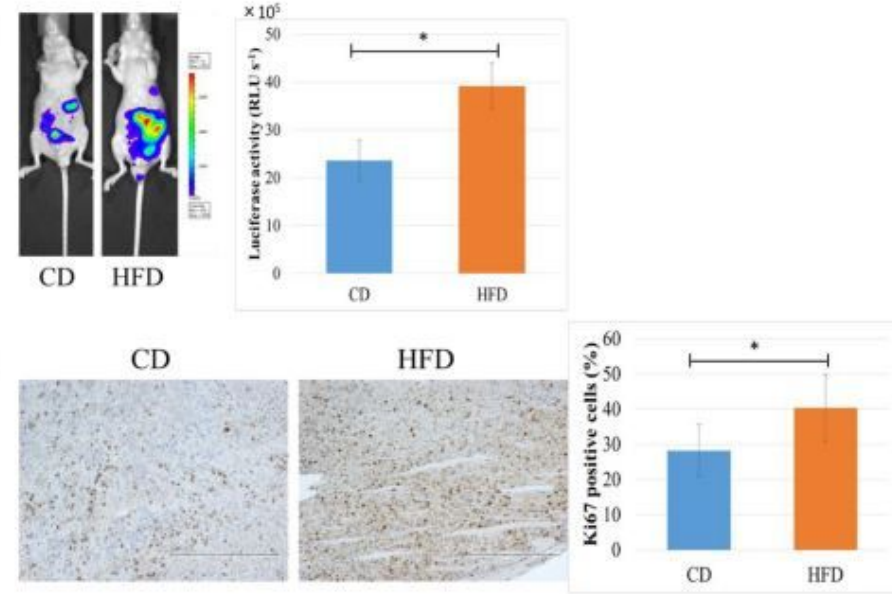

c

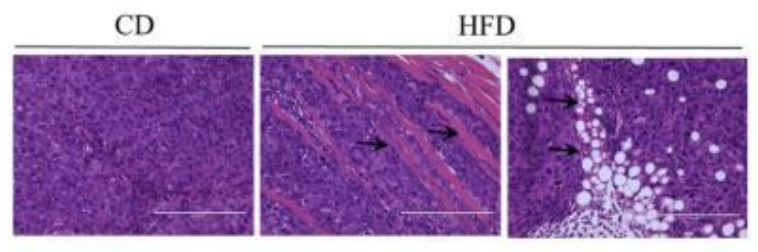

d

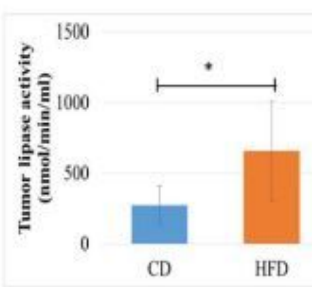

e 1500

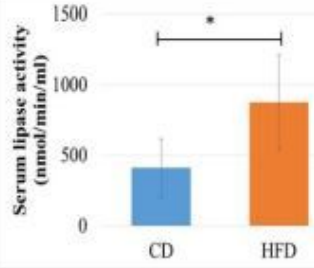

f
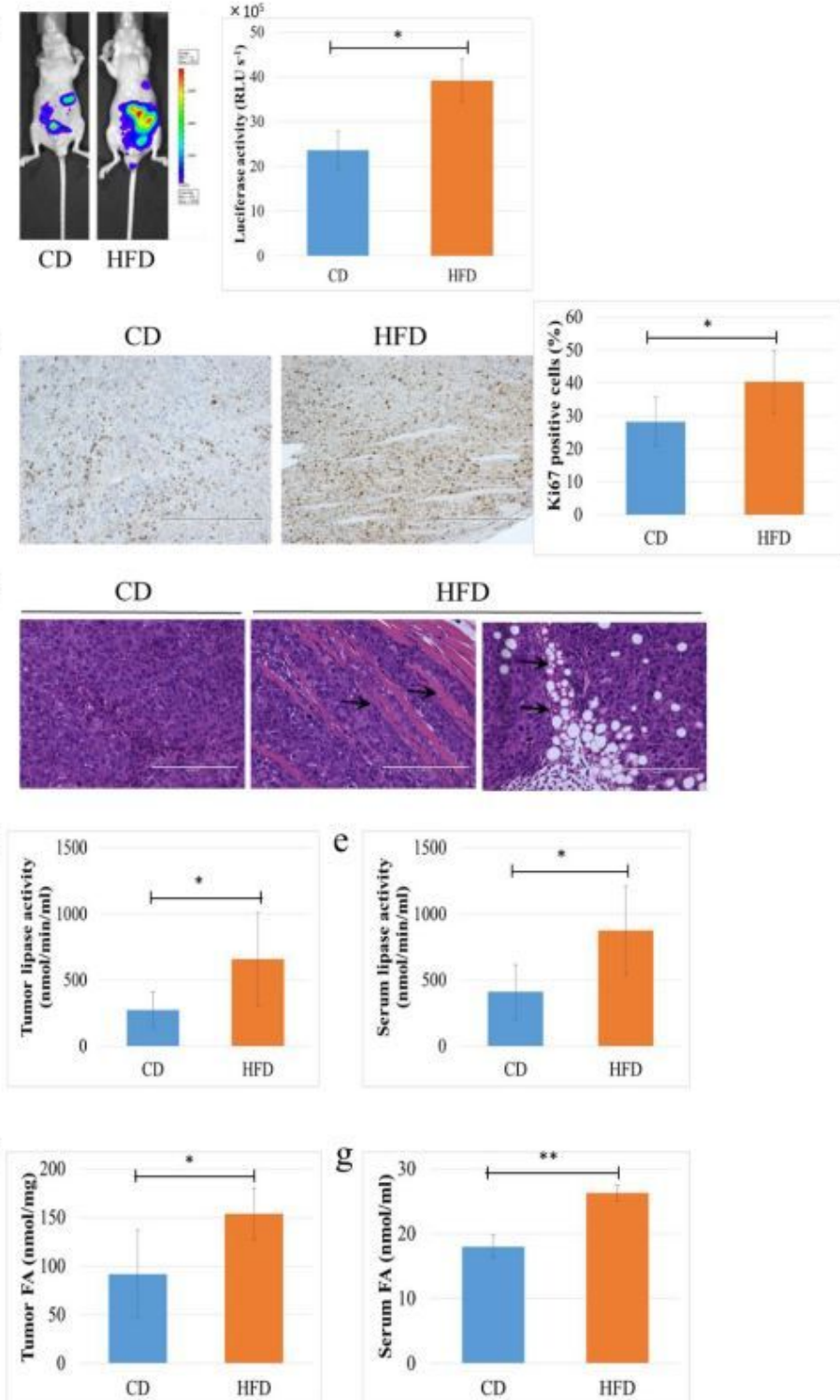

D

g

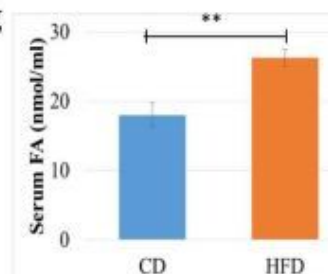

$\mathrm{CD}$

\section{Figure 1}

High-fat diet influenced PCa progression and enhanced adipocyte infiltration and adipolysis in the PCa microenvironment PC-3M-luc-C6 cells were intraperitoneally injected into mice that were randomly 
assigned to either the control diet (CD) group or the high-fat diet (HFD) group (5 per group). a Tumor progression and luciferase activity were measured by the Xenogen IVIS ${ }^{\mathrm{TM}}$ imaging system with intraperitoneal injection of luciferin 4 weeks after injection of the cells. The tumor progression as measured by luciferase activity was significantly higher in the HFD group than the CD group $\left({ }^{*} P<0.05\right)$. $b$ Xenograft tumor sections from mice in the HFD and CD groups were subjected to immunohistological staining with an anti-Ki67 antibody (bar, $100 \mu \mathrm{m}$ ). The Ki67 positivity was significantly higher in the HFD group than the CD group $(28.3 \pm 5.3 \%$ vs $13.9 \pm 2.1 \%$, $* P<0.05)$. $c$ The slides of mouse xenograft tumor tissue were stained with hematoxylin and eosin. The mouse peritoneal tumors showed a higher transmigration of PCa cells into the peritoneal stroma in the HFD group (middle panel, arrow), and stimulated adipocyte infiltration in the tumor microenvironment (right panel, arrow). $d$ and e Lipase activity in the xenograft tumors and the sera of mice was measured using a Lipase activity assay kit. The lipase activity in the tumor and sera were significantly higher in the HFD group than in the CD group ( ${ }^{*}<$ 0.05 and $* P<0.05$, respectively). $g$ and $f$ FFA concentration in the tumor extract and sera of the xenograft mice was measured with a FFA quantification kit. The FFA levels in the tumor and sera were significantly higher in the HFD group than in the CD group ( ${ }^{*} \mathrm{P}<0.05$ and $* * \mathrm{P}<0.01$, respectively).

Fig. 2
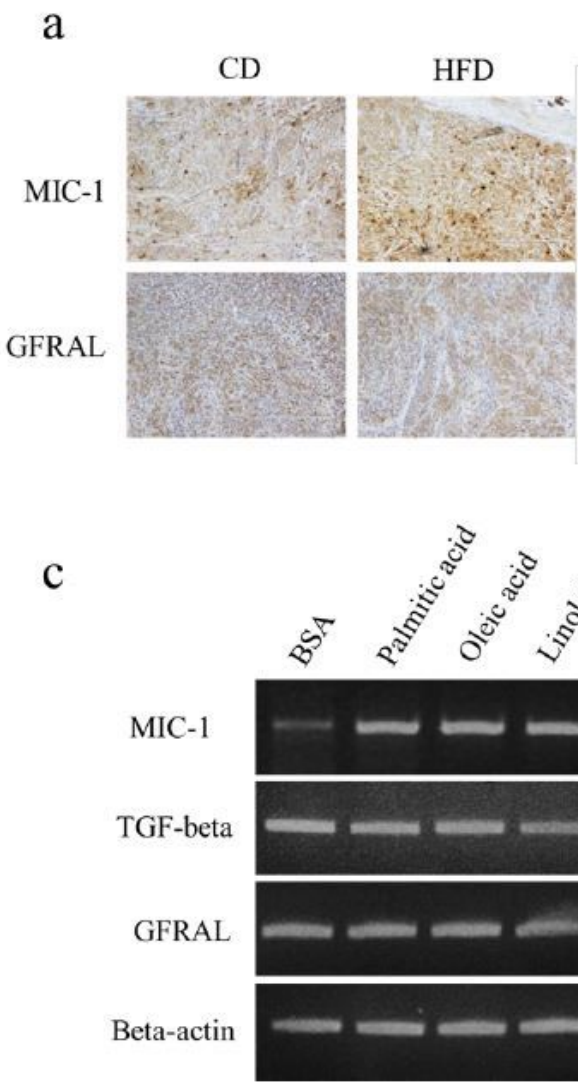

HFD
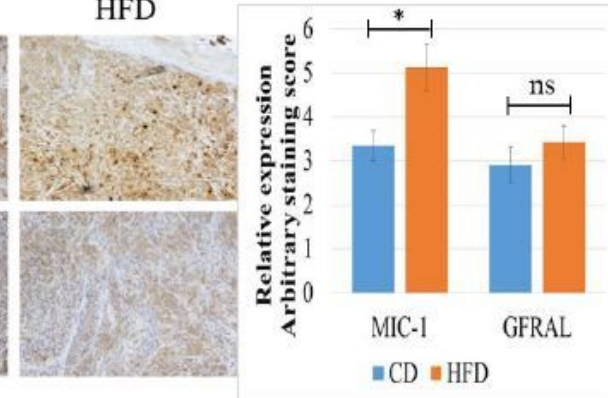

$\approx \mathrm{CD} \| \mathrm{HFD}$

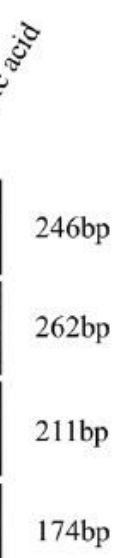

d b
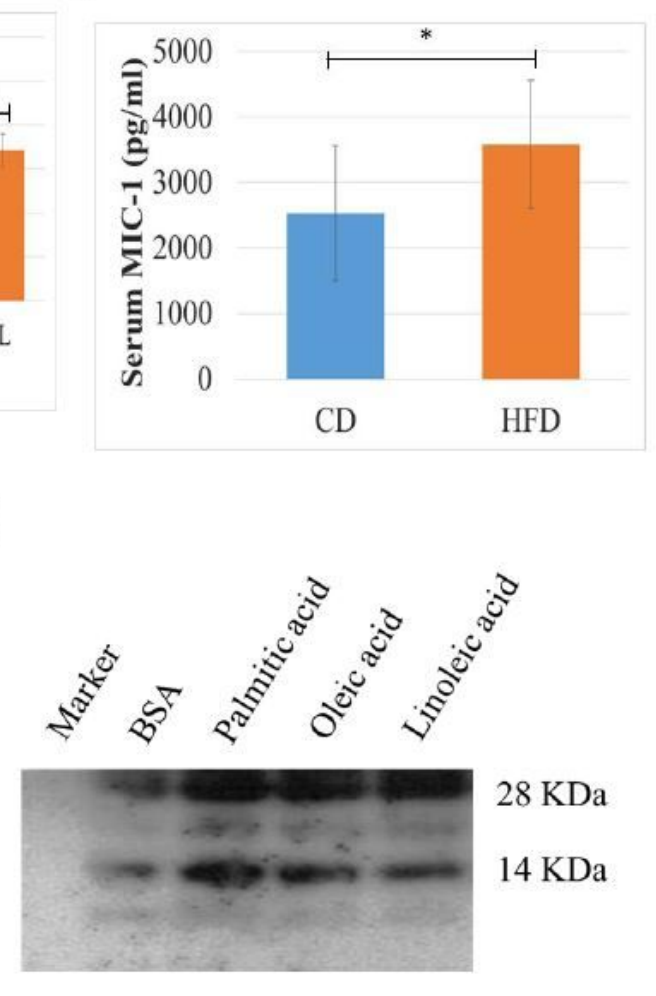

\section{Figure 2}

HFD and exogenous FFAs stimulated the expression and secretion of MIC-1 a The xenograft tumors were stained with antibodies to MIC-1 and GFRAL, and the staining intensity was semi-quantitatively evaluated. The staining level of MIC-1 was significantly higher in the HFD group than the CD group ( ${ }^{*}<$ 0.05), but there was no significant difference in the staining level of GFRAL in the xenograft tumor of the 
two groups. ns: Not significant. b The serum MIC-1 levels were measured by an MIC-1 ELISA kit. The mean serum level of MIC-1 was significantly higher in the HFD group than in the CD group (3506.0 \pm 1888.4 and $\left.2618.8 \pm 710.4 \mathrm{pg} / \mathrm{ml},{ }^{*} \mathrm{P}<0.05\right)$. $\mathrm{c}$ and d $\mathrm{PC}-3$ cells were cultured with $0.125 \mathrm{mmol} / \mathrm{l}$ of $\mathrm{PA}$, $0.25 \mathrm{mmol} / \mathrm{I}$ of OA, $0.15 \mathrm{mmol} / \mathrm{I}$ of LA, or $2 \%$ BSA (as the control) for $24 \mathrm{~h}$. Cells were harvested, total RNA extracted, and quantitative RT-PCR was performed to detect MIC-1, TGF-beta, GFRAL, and beta-actin c. Proteins from equal volumes of the conditioned medium (CM) in the c were subjected to Western blot analysis using an anti-human MIC-1 antibody $\mathrm{d}$.

Fig. 3

a
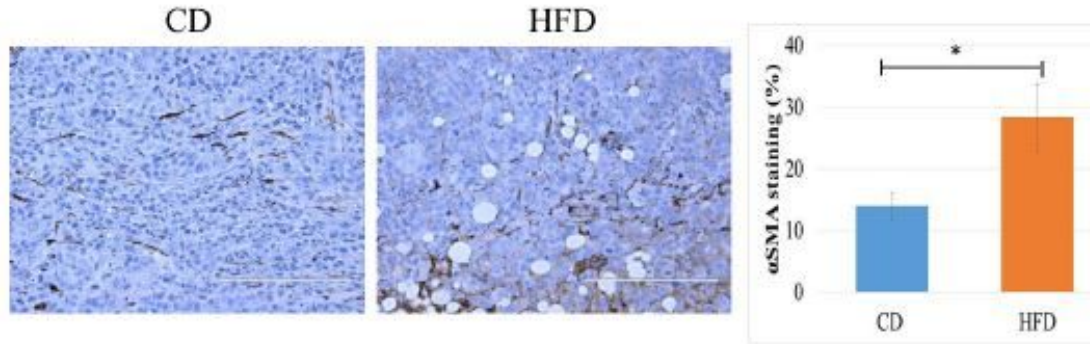

b

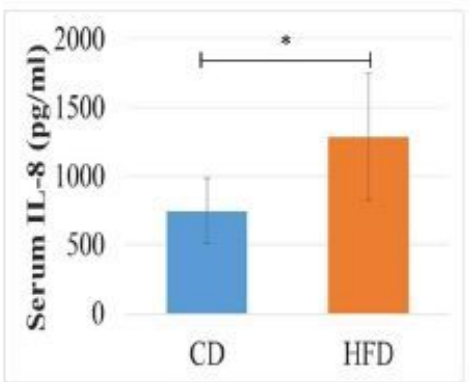

c

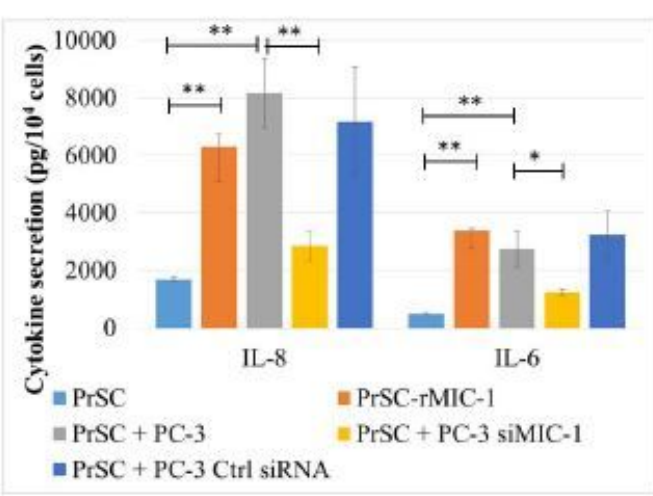

d

$\mathrm{e}$
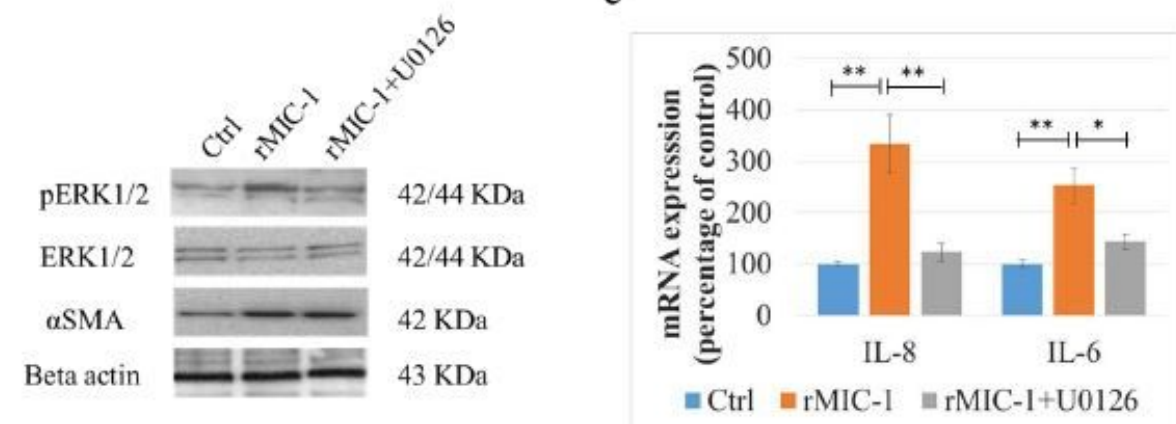

\section{Figure 3}

Activation and cytokine secretion in PCa stromal fibroblasts by the upregulation of MIC-1 under a HFD condition a The xenograft tumors were stained with an aSMA antibody, and the staining level was semiquantitatively evaluated $\left({ }^{*} \mathrm{P}<0.05\right)$. b The serum cytokine level of mice was measured by a cytometric bead array kit (IL-8; $1358.9 \pm 528.5$ vs $773.2 \pm 210.7 \mathrm{pg} / \mathrm{ml}$, $* \mathrm{P}<0.05)$. c Cytokine secretion in PrSC cells stimulated by MIC-1. $4 \times 104$ PrSC cells were treated with $50 \mathrm{ng} / \mathrm{ml} \mathrm{rMIC-1}$ or co-cultured with $2 \times 105$ PC3 cells for $24 \mathrm{~h}$. Some of the PC-3 cells were pretreated with $50 \mathrm{nM}$ MIC-1 siRNA (siMIC-1) or control siRNA (Ctrl siRNA) for $12 \mathrm{~h}$. The IL-8 and IL- 6 levels were significantly higher in the CM of the PrSC cells treated with rMIC-1, or in the CM of the PrSC cells co-cultured with PC-3 cells (IL-8: $1696.8 \pm 82.6$ vs 
$6314.1 \pm 437.0$ vs $8157.9 \pm 1206.8 \mathrm{pg} / 104$ cells; $\mathrm{P}=0.007$ and $\mathrm{P}=0.005$, respectively; and IL-6: $504.2 \pm$ 32.7 vs $3395.1 \pm 68.1$ vs $2743.9 \pm 645.1 \mathrm{pg} / 104$ cells; $P=0.004$ and $P=0.002$, respectively). In addition, IL-8 and IL-6 levels were significantly lower in the CM of the PrSC cells co-cultured with PC-3 cells pretreated with siMIC-1 compared to those co-cultured with untreated PC-3 cells or those treated with Ctrl siRNA (mean $\pm S D ; * P<0.05$ and ${ }^{*} P<<0.01$, respectively). $d$ and e PrSC cells were cultured in the presence or absence of $1 \mu \mathrm{M}$ U0126 for $1 \mathrm{~h}$ before treatment with $50 \mathrm{ng} / \mathrm{ml} \mathrm{rMIC-1}$ for $3 \mathrm{~h}$. d Equal amounts of proteins $(10 \mu \mathrm{g})$ from the cells were subjected to anti- pERK1/2, anti- ERK1/2, anti-aSMA, and anti-beta-actin antibody. e IL-8 and IL- 6 mRNA levels were measured by quantitative RT-PCR, normalized to the mRNA levels of beta-actin $* P<0.05$, and ${ }^{*} * \mathrm{P}<0.01$.

Fig. 4

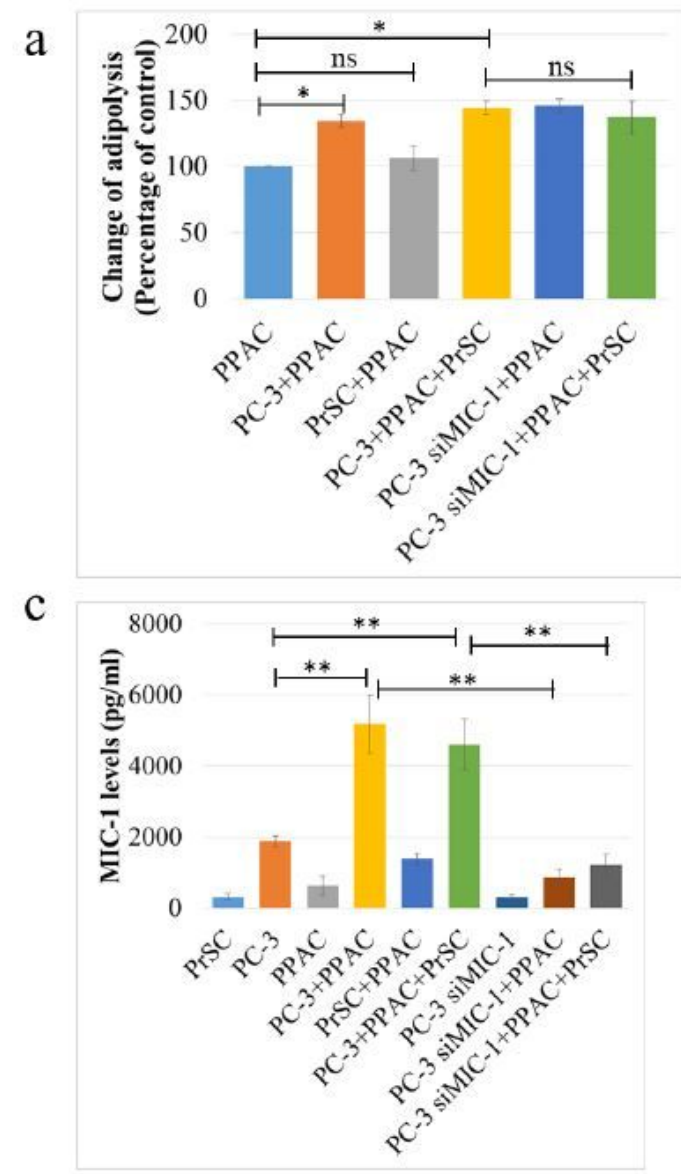

b
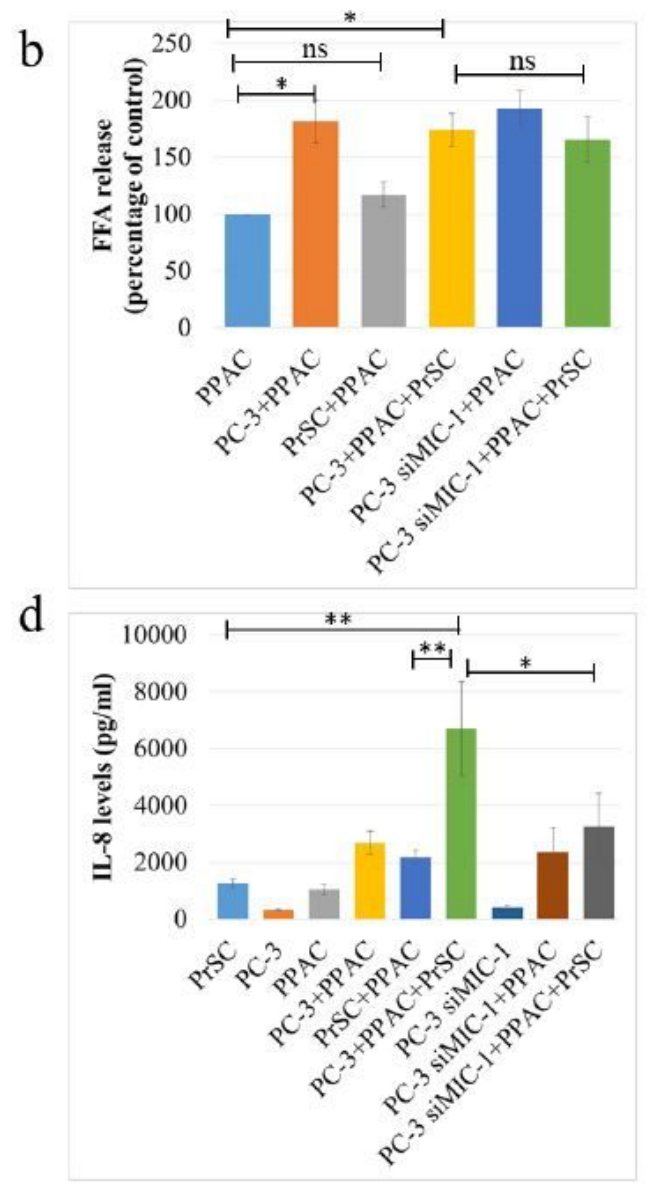

\section{Figure 4}

Periprostatic adipocytes stimulate MIC-1 secretion in PC-3 cells and IL-8 secretion in PrSC cells by upregulating adipolysis and FFA release. The isolated PPAC $(n=13)$ from the radical prostatectomy patients were directly incubated in 6-well plates previously seeded with $2 \times 105$ of PC-3 cells pretreated with $50 \mathrm{nM}$ siMIC-1, and cultured in the presence or $4 \times 104$ of PrSC for $48 \mathrm{~h}$. a and b The levels of adipolysis and FFAs in the conditioned medium (CM) of the PPAC were significantly higher following the co-culture of PPAC and PC-3 cells than those in PPAC culture alone. However, there were no statistical differences in the levels of adipolysis and FFAs in the CM of PPAC co-cultured with PC-3 cells than in those co-cultured with PC-3 cells pretreated with siMIC-1 ( ${ }^{*} P<0.05$ and ${ }^{* * P} P 0.01$ ). ns: No statistical difference. c The MIC-1 level was measured by an MIC-1 ELISA kit, and the mean MIC-1 level was 
significantly higher in the CM of the co-culture of PC-3 cells and PPAC (5178.0 \pm 801.8 and $1883.6 \pm$ $143.1 \mathrm{pg} / \mathrm{ml},{ }^{\star} * \mathrm{P}<0.01$, and $4597.7 \pm 723.0$ and $1883.6 \pm 143.1$, ${ }^{\star \star} \mathrm{P}<0.01$, respectively). The MIC-1 level was significantly decreased in the CM of the PC-3 cells treated with siMIC- 1 in the above co-culture experiments (**P< 0.01). $d$ The IL-8 levels were measured by an IL-8 ELISA kit. The IL-8 levels were significantly higher in the $\mathrm{CM}$ of PrSC cells co-cultured with PPAC, and further in the presence of PC-3 cells compared to those cultured alone or co-cultured with PPAC only $(6697.7 \pm 1673.5$ and $1266.7 \pm$ $147.9 \mathrm{pg} / \mathrm{ml},{ }^{\star} * \mathrm{P}<0.01$. , and $6697.7 \pm 1673.5$ and $2688.4 \pm 401.6,{ }^{\star} * \mathrm{P}<0.01$, respectively). The IL-8 level was significantly decreased in the CM of PrSC cells by co-culture with PPAC and PC-3 cells pretreated with siMIC-1 in the above experiments ( $\left.{ }^{\mathrm{P}}<0.05\right)$.

\section{Fig. 5}

a

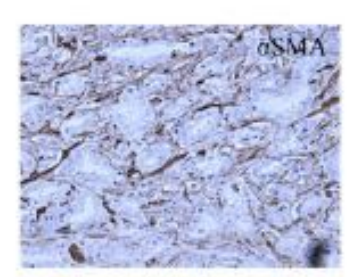

c

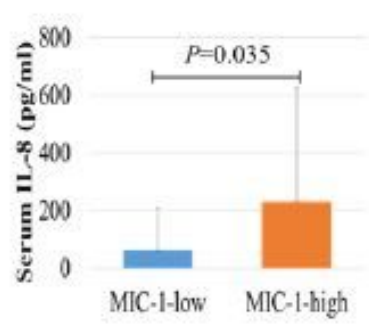

e
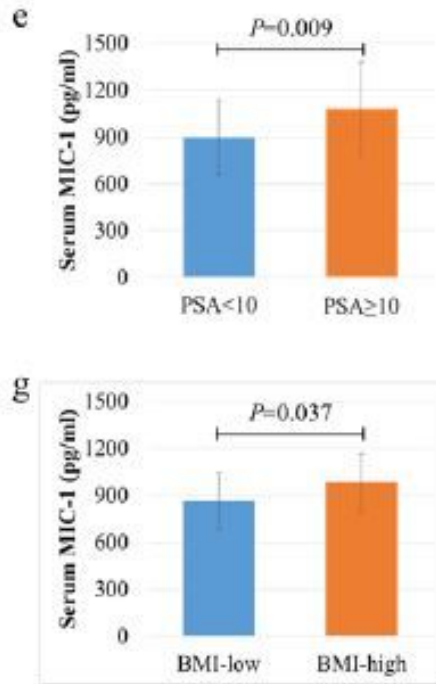

b

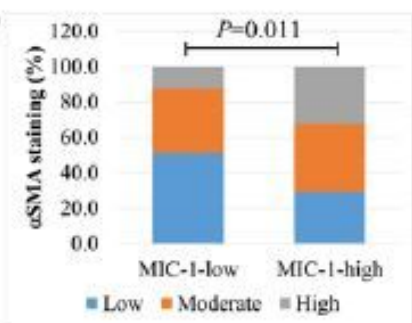

d

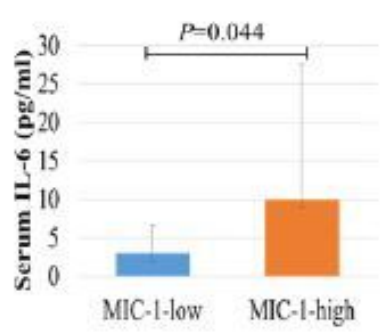

f

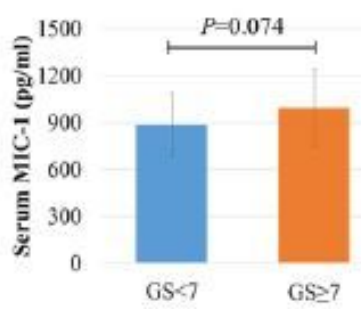

h

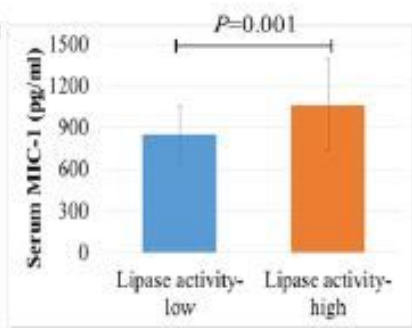

\section{Figure 5}

Overexpression and secretion of MIC-1 was significantly correlated with cancer stroma activation and advanced PCa progression The serum MIC-1 levels in 67 patients with localized PCa were measured using an MIC-1 specific ELISA kit, and the patients were divided into two groups according to the median level of serum MIC-1 (MIC-1-low, $n=33$ and MIC-1-high, $n=34$ ). a The aSMA expression was semi- 
quantitatively evaluated by the proportion of aSMA positive cells in the stroma of the tumor section. $\mathrm{b}$ The patients in the MIC-1-low group, $51.5 \%, 36.4 \%$, and $12.1 \%$ while $29.4 \%, 38.2 \%$, and $32.4 \%$ in the MIC-1high group were classified as having low, moderate, and high aSMA staining, respectively $(P=0.011)$. $c$ and $d$ The serum cytokine concentration was measured by a cytometric bead array kit (IL-8: $230.1 \pm 395.0$ and $61.4 \pm 145.9 \mathrm{pg} / \mathrm{ml} ; \mathrm{P}=0.035$; and IL-6: $10.0 \pm 17.5$ and $3.0 \pm 3.5 \mathrm{pg} / \mathrm{ml} ; \mathrm{P}=0.044$, respectively). e The PCa patients were divided into two groups according to the serum level of PSA (PSA $<10 \mathrm{ng} / \mathrm{dl}, \mathrm{n}=$ 45 , and $P S A \geq 10 \mathrm{ng} / \mathrm{dl}, \mathrm{n}=22$ ). (MIC-1: $897.7 \pm 238.8$ and $1080.1 \pm 297.9 \mathrm{pg} / \mathrm{ml}$, respectively; $P=$ $0.009)$. $f$ The patients were divided into two groups according to Gleason score (GS, $G S<7, n=24$, and GS $\geq 7 ; n=43$ ). (MIC-1: $887.8 \pm 200.6$ and $996.1 \pm 241.7 \mathrm{pg} / \mathrm{ml}$, respectively; $\mathrm{P}=0.074$ ). $\mathrm{g}$ The PCa patients were divided into two groups (BMI-low and BMI-high) according to their median BMI, (MIC-1: $863.3 \pm 179.2, \mathrm{n}=34$, and $984.2 \pm 254.1, \mathrm{n}=33 \mathrm{pg} / \mathrm{ml}$, respectively; $\mathrm{P}=0.037)$. $\mathrm{h}$ The patients were divided into two groups (Lipase activity-low and Lipase activity-high) according to the median serum lipase activity (MIC-1: $845.2 \pm 207.7, n=40$, and $1064.8 \pm 329.1, n=27 \mathrm{pg} / \mathrm{ml}$, respectively; $P=0.001$ ).

Fig. 6

a

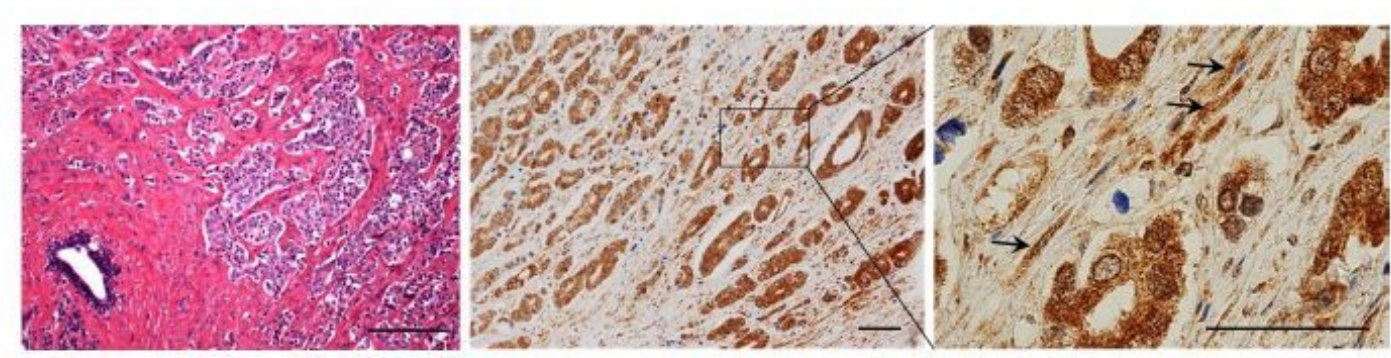

$\mathrm{b}$

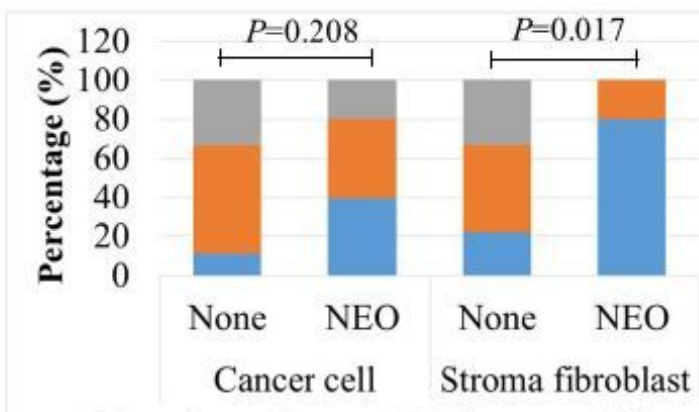

= Negative or Low $=$ Moderate $\quad$ = High

\section{Figure 6}

GFRAL is expressed in prostate cancer cells and the surrounding stromal fibroblasts a Representative images of GFRAL expression. Immunohistological staining of tissue samples from PCa radical prostatectomies with an anti-GFRAL antibody showed that GFRAL was predominantly expressed in the cytoplasm and membrane of cancer cells and stromal fibroblasts (arrow). b The difference in GFRAL 
expression in cancer tissues with or without neoadjuvant treatment was assessed

immunohistochemically. The patients were divided into two groups including those with no preoperative therapy (None, $n=10$ ), neoadjuvant androgen deprivation therapy (ADT), and/or chemotherapy (NEO, $\mathrm{n}=9$ ). The GFRAL staining level in PCa, especially in the stromal fibroblasts, was lower in the NEO group compared to the None group $(P=0.208$ and $P=0.017$, respectively).

\section{Fig. 7}

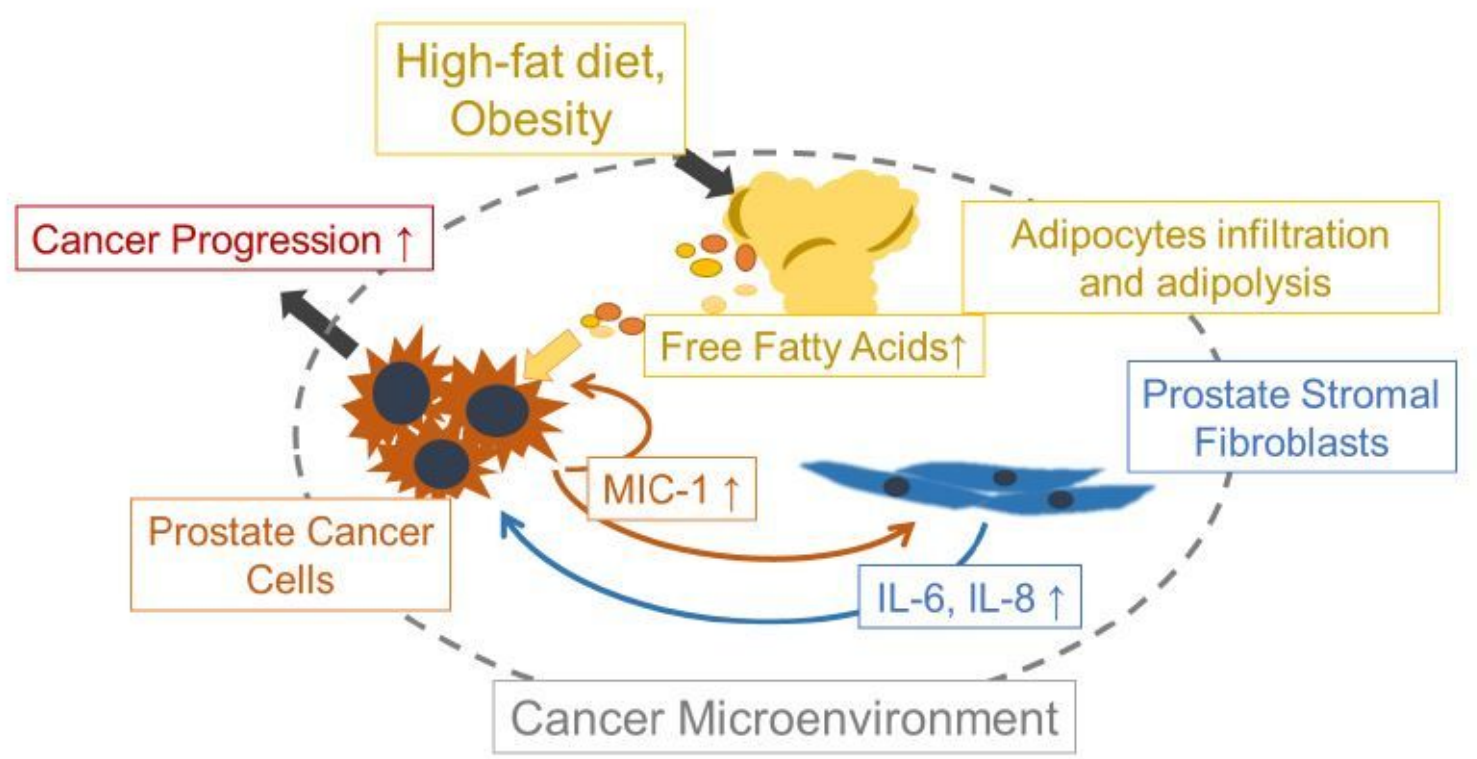

\section{Figure 7}

Schematic role of MIC-1 signaling in the prostate cancer microenvironment under a HFD milieu MIC-1 production was increased in PCa cells, which was affected by adipocyte infiltration and adipolysis. MIC-1 directly stimulated the surrounding PrSC cells to secrete protumorigenic cytokines such as IL-8 and IL-6 in the PCa stromal microenvironment, especially under a HFD condition. These upregulated functional cytokines directly and/or indirectly stimulated PCa cell proliferation, invasion, and metastasis.

\section{Supplementary Files}

This is a list of supplementary files associated with this preprint. Click to download.

- SupplementaryFigurer020727.ppt

- SupplementaryFigurer020727.ppt

- Supplementaryinformaationr020724.doc 
- Supplementaryinformaationr020724.doc

Page 25/25 